\title{
Palma y Vallejo: complementariedad en la crítica literaria romántica
}

\author{
Wellington Castillo Sánchez \\ Universidad Nacional de Trujillo \\ ccyculturvallejo@yahoo.es \\ Trujillo-Perú
}

\section{Resumen}

El presente trabajo trata de mostrar la complementariedad que se da en la crítica literaria romántica entre Ricardo Palma y César Vallejo, dos de los escritores peruanos más importantes y estudiados, ambos pertenecientes al romanticismo, el primero de manera plena, el segundo en los años terminales de este movimiento; por tanto, en diferentes tiempos, circunstancias y particularidades, pero en el mismo interés de valorar a escritores románticos, entre ellos a Arnaldo Márquez, Luis Benjamín Cisneros y Carlos Augusto Salaverry, miembros del grupo de la bohemia de Palma.

Acudimos al método de la complejidad, dentro de este, a la movilización de la categoría de intertextualidad, a la validez epistemológica de la crítica literaria efectuada por ambos escritores, para encontrar las valoraciones objetivas, logro de esta tarea.

Palabras clave: complementariedad, crítica literaria romántica, complejidad, intertextualidad, validez epistemológica.

\section{Abstract}

The purpose of this article is to show the complementarity that occurs in the romantic literary criticism between Ricardo Palma and Cesar Vallejo, two of the most important and studied Peruvian writers, being both part of the Romanticism, the first one in a fully developed way, and the second one in the last years of this movement; therefore, in different times, circumstances and particularities, but in the same interest of valuing romantic writers, we include Arnaldo Márquez, Luis Benjamin Cisneros and Carlos Augusto Salaverry, members of Palma's bohemian group. 
We resort to the method of complexity, within this, the mobilization of the category of intertextuality, and the epistemological validity of the literary criticism made by both writers to find the objective evaluations, which is the purpose of this task.

Keywords: complementarity, romantic literary criticism, complexity, intertextuality, epistemological validity.

\section{Wellington Castillo Sánchez (Trujillo)}

Dramaturgo, ensayista, poeta, promotor cultural. Actualmente es docente de Pre y Posgrado de la Universidad Nacional de Trujillo. Premio Nacional de Teatro Sebastián Salazar Bondy 1989. Ha publicado teatro, poesía, ensayo y narrativa. 


\section{Introducción}

Unir a Palma y a Vallejo en los logros de una tarea de crítica literaria romántica, que denominamos complementaria, necesita de algunas consideraciones previas, sin pretender hacer comparaciones.

Primero, Palma, tras una larga trayectoria no sin avatares, pero colmada de gloria por la producción y sucesivas ediciones de su serie de Tradiciones peruanas, fallece en octubre de 1919; Vallejo se había establecido en Lima desde 1918, permaneciendo todo el año 1919, tiempos difíciles para su vida, pero auspiciosos para sus logros literarios: había preparado el corpus de poemas para su primer libro Los heraldos negros, cuya edición finalmente se publicó en julio de 1919, e inició y continuó la escritura de los que conformarían Trilce, con los cuales llegó al vanguardismo.

Segundo, ambos autores son de filiación romántica; Palma a plenitud, Vallejo en los últimos años de influencia de este movimiento; más aún, la creación del género tradición Palma la logra dentro del romanticismo; aunque intentó cultivar la leyenda histórica a juicio de Riva Agüero (1962), «estaba reservado encontrar con sus Tradiciones la única forma de adaptación que tuvo el género legendario entre nosotros» ( $p$. 37); Vallejo rindió tributo a su formación romántica con una brillante tesis titulada El romanticismo en la poesía castellana, sustentada para optar el grado de bachiller en el año 1915, pero en el proceso de su creación poética superó la influencia de esta escuela en su obra Los heraldos negros, con la cual consagró, y a su vez, avanzó más allá del modernismo.

Tercero, expresión de su generación, Vallejo, desde 1916, en Trujillo, respondía y era coherente al movimiento del modernismo; por esa razón, en Lima, estaba cerca a Valdelomar, 
González Prada, y Eguren. Nos lo muestran las sucesivas crónicas «Con el Conde de Lemos», «Con Manuel González Prada», «Con José María Eguren», «Comentario sobre la obra de Abraham Valdelomar» (1918); y aquella sentida y llorada, titulada «Abraham Valdelomar ha muerto», publicada en el diario La Prensa el 4 de noviembre de 1919, casi un mes después del fallecimiento de Palma (Vallejo, 1954, pp. 29-41).

Cuarto, dentro de este aparente distanciamiento, Vallejo tenía a Palma en alta valoración. Desde Europa, en su crónica «La Vida Hispanoamericana. Literatura Peruana. La Última Generación» (1924), en la cual afirma que tras la generación de Chocano y los García Calderón «hay un jalón de tiempo casi del todo estéril en la literatura del Perú», escribe:

Dos únicos escritores salvan este árido lapso: Leonidas Yerovi y José Lora y Lora [...]. Toda la obra del primero -teatro, poesía- acusa una innegable personalidad, caracterizada por aquel criollismo peruano que en el pasado cuenta con figuras tan eminentes como Ricardo Palma y Manuel Asencio Segura. (Puccinelli, 1967, p. 18)

Quinto, la presente investigación tiene como una de sus fuentes fundamentales la obra La bohemia de mi tiempo, publicada por Palma en 1887. Escrita en tono confidencial y en su estilo humorístico, desde luego, debemos tomarlo en cuenta y conservarlo, aunque pueda poner en tela de juicio el valor de este trabajo que plantea una tarea de crítica romántica, allí donde puede considerarse que no la hay, no solo por el tono y estilo señalado sino por lo que Palma (1961) dice expresamente en el acápite II: «En fin, que no me he propuesto escribir un ensayo de crítica literaria» (p. 1295). 
Recordemos al respecto, lo que expresa Riva Agüero (1962)

Don Ricardo Palma ha consignado sobre este período noticias y anécdotas muy curiosas en su Bohemia de mi tiempo, que no es libro de crítica, sino de confidencias literarias, pero en el cual incidentalmente se encuentran bastantes apreciaciones que por su tono benévolo y encomiástico revelan al amigo y compañero de los escritores allí mencionados. Es necesario reconocer que la disculpable y simpática indulgencia de Palma hace concebir de nuestra generación romántica una idea superior a lo que realmente fue (p. 138).

Sobre el juicio citado, podemos apreciar que el Maestro, consciente de su estilo y su dicho, ya había advertido de esta forma de mirar y juzgar su Bohemia. Con mucha sencillez y claridad, Palma (1961) avizora:

Quizá, los que ahora lean estas mis confidencias, vean en sus párrafos sólo un desahogo de fatuidad insustancial; pero sé que, cuando el presente sea lejano pasado, estas páginas serán estimadas por los desempolvadores de antiguallas, tanto como yo aprecio y aquilato hogaño la charla anecdótica de los viejos cronistas de convento (p. 1293).

Pese a esta advertencia, en la crítica todavía persisten dudas, serias observaciones, valoraciones diversas sobre La bohemia de mi tiempo, que hacen, como señala Holguín Callo (2010), que esté «lejos de pretender la factura de un sesudo estudio socio-cultural» y más bien sea «una obra que guarda secretos» que todavía hay que revelar (p. 138). Pero si sopesamos bien las citas arriba anotadas, por los términos «aprecio y aquilato» o «apreciaciones» benévolas o encomiásticas, que ambas encierran, encontraremos el necesario status epistemológico para conferir valor no solo a los datos sino a las apreciaciones, juicios y valoraciones que expresa Palma sobre la personalidad 
y la obra de los «matriculados» del grupo romántico, en todo el texto de La bohemia de mi tiempo, que por ser testimonial son susceptibles de ser aceptadas o refutadas ${ }^{1}$.

Otra de las fuentes fundamentales de este artículo es la tesis de Vallejo, ya señalada. Texto literario de rango académico, no solo nos ofrece el marco teórico general y particular, al haber Vallejo delimitado el tema a la poesía y al espacio geográfico de España, al cual nos ligamos, sino también la base para dar validez a la ponencia al desplegar una crítica literaria rigurosa, fundada por

Los hermanos Schlegel, que sin disputa representan esta epifanía, tienen la gloria de haber fundado de este modo, el mejor instrumento con el que nuestros tiempos se registran científicamente las diversas manifestaciones del arte bello. Desde entonces la crítica ha dejado de ser el ligero análisis de las formas y la observación más o menos incompleta de una manera determinada de la técnica, para convertirse en el juicio amplio y profundo, resultado de una visión

I Consideramos que todavía resta una tarea sobre la importancia de La bohemia de mi tiempo para la literatura nacional, teniendo en cuenta que después de la presentación de la tesis titulada La Literatura en el Coloniaje, 1890, de Eleazar Boloña y Dañino, se inició la llamada «orientación nacionalista», de las tesis relacionadas con el estudio de nuestra literatura, tales como Manuel Asencio Segura, 1898, de Fernando Panizo; Carácter de la Literatura del Perú Independiente (1905), de José de la Riva-Agüero; La vida intelectual de la Colonia (1909), de Felipe Barreda y Laos; asimismo, de integrantes del grupo bohemio de Palma; también, Clemente Althaus, de Alfredo González Prada; Manuel Asencio Segura, de Eduardo Garland Roel; sobre Felipe Pardo y Aliaga, de Pedro Fernández Oviedo; la tesis de doctorado Posibilidad de una Genuina Literatura Nacional (1915), del poeta José Gálvez; el ensayo sobre José Arnaldo Márquez, de Teodomiro González Elejalde; recientemente, la ponencia Asisclo Villarán y su poesía festiva y romántica en La Bohemia de Palma (201 I) de Manuel Pantigoso Pecero. Ver La Orientación Nacionalista en la Facultad de Letras. El peruanismo en la tesis, artículo de Jorge Guillermo Leguía (1918), en Eleazar Boloña. Escritos Literarios, de Jorge Puccinelli, pp. 471-473. 
científica hecha a través de un prisma, de cuyas múltiples facetas, concurren en armoniosa teoría, muchas luces a una alta y vigorosa conclusión (1954, p. 9)

La aplicación de esta crítica, integrada a la opción del principio de Taine de que el arte es fruto de la síntesis de la fusión de la raza, el medio y el momento (la tríada de Taine), como método garantiza, a su vez, la validez y confiabilidad de las valoraciones que ofrece Vallejo en la sección «Poetas románticos peruanos» de su tesis.

De modo que las afirmaciones y/o conclusiones expresadas por ambos escritores en la crítica que hacen a los tres bohemios románticos que tratamos en la ponencia, poseen validez epistemológica y una relación de complementariedad.

\section{El movimiento del romanticismo}

Los movimientos y cambios revolucionarios que se dieron en el siglo XVIII, influenciaron en la renovación de la filosofía, el arte, la literatura, la música, la pintura e, inclusive, la política, generando a finales de aquel siglo el movimiento cultural llamado Romanticismo, que se extendió por toda Europa hasta mediados del siglo XIX.

El romanticismo vino de Alemania e Inglaterra, pasó a Francia, Italia y luego a España; fue un período de florecimiento, de fecundidad. No es fácil resumir el venero cultural que traía y expandía; señalamos la exaltación a la sensibilidad emocional, a la subjetividad, por tanto, a la individualidad y la preeminencia del yo; el ansia de gloria; la glorificación de la belleza y de los ideales; la revelación de la conciencia humana, abismal y de trágicas grandezas; la libertad estética; el amor a la naturaleza; el acrecentamiento del nacionalismo, que impulsó las literaturas nacionales. En arte y literatura fue una reacción contra los 
rígidos cánones del clasicismo y neoclasicismo representados por Boileau y Racine, y el racionalismo de la Ilustración, agotados e incapaces de resolver todo lo que traía el nuevo espíritu de esa época. Aparecieron los mayores escritores del mundo: Goethe, Schiller, Heine, en Alemania; Wordsworth, Coleridge, Shelley, Scott, Byron, en Inglaterra; Hugo, Lamartine, Vigny, Musset, en Francia; Leopardi, Manzoni, en Italia; Espronceda, Zorrilla, Arolas, en España. Pese a tener un lado reaccionario, al ensalzar a la Edad Media, inclusive, uno oscuro o «negro», este movimiento enrumbó lo mejor de la cultura moderna occidental; dentro de él se reestructuró la lírica, género que mayormente se cultivó y dio sus mejores frutos, renovándose la dramática, la épica, la novela, la historia y la crítica literaria. Su fuerza ha sido tal que las escuelas y direcciones del arte que advinieron posteriormente recibieron su influencia.

El Romanticismo expresó una manera de sentir, de concebir la naturaleza, la vida y el hombre mismo, situación que permitió se desarrollara de manera diferente en cada país. Uno de los últimos países europeos a los cuales llegó el romanticismo bajo la influencia inglesa y francesa fue España. Podemos afirmar que los románticos españoles Zorrilla, Espronceda, Enrique Gil, Arolas, el duque de Rivas, imitan y copian a Goethe, Schiller, Shakespeare, Chateaubriand, Milton, Lord Byron, Víctor Hugo, Lamartine, Musset, Walter Scott, Moore. Sin embargo, la crítica considera que el romanticismo español fue original en dos aspectos: en la verbosidad deslumbrante y la producción de una forma de drama y un género de leyenda, digno del trabajo de Lope de Vega, y en la renovación de la tradición del romance añejo. Drama histórico y leyenda, se afirma, son la expresión castiza del romanticismo español. 


\section{El romanticismo en el Perú}

De España pasó el romanticismo a los países Latinoamericanos y, desde luego, a Perú. Y aunque Francia marcaba la influencia de la actividad literaria, la generación romántica peruana como veremos- prefirió a los románticos españoles. En su tesis, Vallejo dice:

El Romanticismo fue objeto de gran entusiasmo por parte de la mentalidad Latinoamericana; y no podía ser de otro modo. Ligados nosotros a España por vínculos de sangre, idioma, religión e historia, tenemos razón para sentir en nuestro espíritu todo movimiento que se opere en aquel pueblo (1954, p. 60).

Este rasgo fue muy acentuado en los países de «HispanoAmérica» durante las primeras épocas de nuestra independencia política, como afirma Vallejo marcando ya una posición de tiempos diferentes, era

Una mera proyección de las formas de actividad española, porque a pesar de que, al proclamar nuestra autonomía, había una cultura de cierta importancia entre nosotros, sin embargo, por muchos años no hemos podido ni podemos aún vivir sin dejar de imitar a los pueblos europeos. La literatura peruana de casi todo el siglo XIX es un perfecto romanticismo; y gran popularidad han tenido y tienen aún entre nosotros Zorrilla y Espronceda" (ibíd.).

Pantigoso Pecero (2009), confirmando este rasgo de nuestra literatura, afirma: «En general, los románticos peruanos abordaron todos los campos de la literatura y tuvieron éxitos fugaces pero impresionantes. Con la mirada puesta en Europa hicieron poesía, teatro, panfleto y novela» (p. 165). Los románticos peruanos imitaron el drama histórico, aquello que 
fue el mejor logro de España, género que fracasó, dándose el logro mayor en la lírica, como enjuicia Palma.

\section{El tiempo y la generación de la bohemia de Palma}

Según Palma, después de un largo periodo de revoluciones y motines, consecuencia de nuestra prematura independencia, sucedió «una era de paz, orden y garantías», en la cual, para impulsar la educación, llegaba de España don Sebastián Lorente (Suárez-Murias, 1967, p. 122)2 , quien sería rector del Colegio de Guadalupe, en cuyas aulas «ante un crecido concurso daba lecciones orales de Historia y Literatura». Es en este tiempo y ambiente que «de 1848 a 1860 se desarrolló, en el Perú, la filoxera literaria, o sea, pasión febril por la literatura», abriéndose para la juventud «nuevos y espléndidos horizontes» ${ }^{3}$.

Esta juventud o nueva generación, recuerda Palma (1961) la conformaban:

Arnaldo Márquez, Nicolás Corpancho, Adolfo García, Numa Pompilio Llona, Clemente Althaus, Luis Cisneros, Carlos Augusto Salaverry, Enrique Alvarado, José Antonio Lavalle, Marian Amézaga, Francisco Lazo, Juan Arguedas, Trinidad Fernández, Toribio Mansilla, Melchor Pasto, Benito Bonifaz, Juan Sánchez Silva, Pedro Paz Soldán y Unanue, Constantino Carrasco, Acisclo Villarán, Juan de

2 Don Sebastián Lorente, llegó a Lima en 1842; nombrado rector del Colegio de Guadalupe, enseñó historia y literatura. Más tarde, fue decano de la Facultad de Letras de la Universidad de San Marcos. Entre otras obras de mérito, dio a la prensa una historia de la Conquista y otra de la época colonial. Murió a fines de 1884 .

3 Algunos estudiosos no están de acuerdo con que el inicio del romanticismo en el Perú sea el año 1848 señalado por Palma. El romanticismo europeo dejaba de existir entre 1845-1850, años en que «comenzaba a penetrar en el Perú», cuyo destino ha sido estar atenido «a la antepenúltima moda europea». Ver Riva-Agüero, 1962. p. 135. 
los Heros, los hermanos Pérez, Narciso Aréstegui, y dos o tres nombres más que, por el momento, se escapan, hacían sus primeros versos y borroneaban su primera prosa, desde los claustros del colegio (p. 1293).

Deslindada de la generación anterior, «literatos que empezaban a peinar canas» $\mathrm{y}$ «en reducida cifra», respondía a todo aquello que le traía el movimiento del romanticismo, entonces, revolucionario y cada bohemio escogió a su ídolo. Palma, testimonia:

Nosotros [...] arrastrados por lo novedoso del libérrimo romanticismo en boga a la sazón, desdeñábamos todo lo que a clasicismo tiránico apestara, y nos dábamos un hartazgo de Hugo y Byron, Espronceda, García Tassara y Enrique Gil. Márquez se sabía de coro a Lamartine; Corpancho no equivocaba letra de Zorrilla; para Adolfo García, más allá de Arolas no había poeta; Llona se entusiasmaba con Leopardi; Fernández, hasta en sueños recitaba las dolorosas de Campoamor; y así cada cual tenía su vate predilecto entre los de la pléyade de revolucionarios del mundo viejo. De mí recuerdo que hablarme de Macías, de Larra, o de las Capilladas, de Fray Gerundio, era darme por la vena del gusto (p. 1294)

Suárez-Murias señala que la generación romántica del Perú

Se formó bajo la tutela e influencia de dos españoles y recibió el estímulo intelectual de emigrados políticos de casi todas las naciones sudamericanas. El tutor de la nueva generación fue el español Sebastián Lorente, que se distinguió como profesor e historiador (1963, p. 122)

Y que Palma elogia: «era un innovador -dice Murias- de gran talento, y la victoria fue suya en la lucha con los rutinarios. La 
nueva generación lo seguía y escuchaba como a un apóstol» (1961, p. 1293)

El otro español fue Fernando Velarde, de quien, el mismo Suárez-Murias, (1963) dice:

Capitaneaba la bohemia estudiantil, el poeta español Fernando Valverde. Oriundo de Santander, había vivido en Cuba. Llegó a Lima, a los veinticuatro años, en 1847. Durante sus ocho años de estadía en la Capital, ejerció tan poderosa influencia entre los estudiantes del «48», como el nombrado José Joaquín de Mora sobre la generación anterior (p. 123)

A este liderazgo indiscutible de Velarde, Palma (1961) lo describe así:

Gran capitán de la bohemia limeña era un poeta español, oriundo de las montañas de Santander, mancebo de robusta y ardorosa fantasía, cuyas composiciones nos cautivaban por lo musical de ellas, y por la elevación, un tanto apocalíptica, de las imágenes. En los fluidos y armoniosos versos de Fernando Velarde, encontrábamos un vago perfume de idealismo y de misterio. Para nosotros no era un poeta discutible, sino un poeta que se imponía. Lo admirábamos... porque sí (p. 1294).

Los emigrados románticos que vinieron y residieron en Lima por un tiempo y contribuyeron con su trabajo literario a la bohemia, según Suárez-Murias (1963), fueron: Juana Manuela Gorritti, de Argentina; Juan Vicente y Simón Camacho, costumbristas venezolanos; el costumbrista ecuatoriano Nicolás Augusto González y el poeta ecuatoriano Numa Pompilio Llona (p. 123). 
Pasemos ahora, a la valoración de los tres bohemios «matriculados» «de la filoxera», de los cuales se ocupan Palma y Vallejo, en diferentes tiempos: Arnaldo Márquez, Luis Benjamín Cisneros y Carlos Augusto Salaverry.

\section{Arnaldo Márquez (1830-1904)}

Revelando el fuerte rasgo de influencia e imitación que nuestros literatos románticos acentuaron en su trabajo literario al privilegiar el género dramático, Palma (1961) en La Bohemia de mi tiempo, y en su estilo, escribe:

Para los escritores noveles no hay aplausos más codiciados que los obtenidos sobre el escenario teatral. Aquello de oír, en todos los tonos, el grito de «iEl autor! iQue salga el autor!», repetido a la vez, por mil bocas, es para enloquecer a todo muchacho aspirante a sentar plaza de hijo mimado de las musas (p. 1299).

Luego señala que fue Márquez «el primero de los bohemios que, sin encomendarse a Dios ni al diablo, se lanzó a escribir para el teatro» y empezó «con algo que él llamaba drama patriótico» titulado La bandera de Ayacucho, sobre el que Palma confesó no saber cómo llamarlo; deslindó más bien que Márquez era «uno de los más notables líricos» y asentó una valoración negativa de su teatro:

Los versos de Márquez, que es, como Salaverry, Althaus y García, uno de los más notables líricos contemporáneos, entusiasmaron al público; pero argumento, caracteres y situaciones dramáticas no había en La bandera de Ayacucho.

Pocos meses después dio a la escena Pablo o la familia del mendigo y La cartera del ministro, dramas no menos 
desventurados que el anterior en cuanto a condiciones de arte, pero bellísimamente versificados (p. 1300)

Testimonia don Ricardo que Márquez, mozo de talento, por consejos de Ignacio Novoa, se convenció de que sus producciones teatrales solo le llevarían a los aplausos de una noche, «que en su lira no tenían resonancia la tragedia, el drama, ni la comedia, y no volvió a reincidir en el pecado» y, en un juicio acertado del valor de la escritura de Márquez en la lírica, da «fe que su nombre literario ganó en ello» (ibíd.). Este final señalado lo remite a una nota de pie de página que la citamos no solo por los datos adicionales que ofrece, sino también por los juicios valorativos conque lo elogia. Palma señala:

Con el título de Notas perdidas, llegó a publicar Márquez, en 1862, dos tomitos de poesías. Ha escrito, en verso, mucho y muy bueno: pero sus mejores composiciones andan dispersas en los periódicos. Recientemente ha publicado en Barcelona dos volúmenes conteniendo sus traducciones del teatro de Shakespeare (ibíd.).

Vallejo en su tesis, señalaba en el acápite «Poetas románticos peruanos», entre otros, un juicio muy interesante cuyos alcances coinciden plenamente con los de Palma:

Pues el Romanticismo entre nosotros tuvo en algunos poetas un carácter original en cuanto la poesía tomó un pronunciado sabor ligero y ágil de sal asiática, y en cuanto las costumbres, carácter e ideas populares, al pasar a los dominios del arte, ocultan la personalidad del poeta. Don Felipe fue pues humorista y amante de pintar las costumbres nacionales, exteriorizándolas, en bien cortados sonetos y bellísimas letrillas (1954, p. 61). 
A continuación, se ocupa de Salaverry y Márquez, anotando:

Consideramos a Carlos Augusto Salaverry y Arnaldo Márquez, a quien estimaba tanto el padre Zorrilla, sin duda porque veía en él a un hermano suyo en Apolo. Citamos a estos dos poetas juntamente, porque encontramos una gran semejanza entre sus temperamentos artísticos. El primero militar y el segundo diplomático, los dos han cantado en dulcísimas elegías el sentimentalismo romántico más penetrante (ibid.).

Entonces señala el tema general y favorito de inspiración de ambos poetas: el amor, «en Salaverry, a un ángel, como él llama a la mujer objeto de sus sueños; y en Márquez, el amor a su madre» (ibíd.); tema que, años más tarde, Vallejo tratará magistralmente.

Pero particularizando a Márquez y mencionando a Lamartine, quien decía que

Al escribir un verso, lo primero que sentía era una disposición musical sin saber aún qué idea iba a desarrollar, y que todavía mucho después acudía el pensamiento, es decir, le ocurría lo que, en virtud de las leyes de la génesis del verso, ocurre a todo poeta verdadero: primero la emoción y después la idea (ibíd., p. 62).

Vallejo señala además:

A Márquez le pasaba lo mismo; casi todas sus poesías empiezan por una mera armonía para entrar después a la concepción general del poema, de lo que nos da una idea la composición titulada «A solas» en que empieza diciendo:

Mi corazón reboza de armonía. 
Y después, sabe llorar amargamente pensando en la miseria humana, gimiendo que:

El cielo tiene luz, la flor rocío, y hasta las olas de los turbios mares visten de espumas el azul salobre...

Yo sólo tengo lágrimas... iSoy pobre! (ibíd.)

Vallejo añade que es «la falta de esperanza que guíe a manera de una estrella al corazón despedazado por el dolor profundo, le hacía cantar en lamento sincero, lleno de pesimismo, en un momento de desengaño» (ibíd.), y concluye con la siguiente valoración que la citamos aparte para dimensionar su calidad:

Un verso que por su alta filosofía vale por todo un poema y es digno del mismo Espronceda; esto es cuando se dirige a su tierna madre que acongojada vela, para ayudarla a sufrir diciéndole:

¡Quién te dará, aunque mienta, una esperanza! (ibíd.) ${ }^{4}$

Podemos agregar, por oposición a lo que Vallejo afirma de Salaverry, que Márquez es un poeta que tiene un acentuado rasgo místico (ibíd.).

4 Vallejo (1954) confiesa en su tesis las profundas emociones que sentía por la lectura de los versos de Márquez y su propósito de estudiarlo de manera «especial y detenida»; a la vez, la imposibilidad de conseguir todas sus poesías. Nos preguntamos ¿́cómo conocía Vallejo a Márquez? Se sabe ahora que Arnaldo Márquez publico Notas perdidas, en 1862 y 1878; Prosa y Verso, en Lima, en 1901, y el poema «Canto a San Martín», el mismo año y que colaboró en diversos periódicos del país y del extranjero en los cuales publicó sus poesías. 


\section{Luis Benjamín Cisneros (1937- 1904)}

Al recordar a Cisneros y su obra, Palma muestra otra vez el rasgo de influencia que sufre nuestra literatura, enjuiciando sus virtudes y debilidades. Dice Palma (1961):

Se contagió con el mal ejemplo que le dimos, y escribió una alegoría patriótica, en un acto, El Pabellón peruano, que, francamente, es bellísima y le mereció justa ovación. Algunos meses más tarde produjo su musa un drama en cuatro actos Alfredo el sevillano; en medio de grandes defectos, tiene situaciones de interés dramático (p. 1302).

Cuando Palma dice que Cisneros «se contagió del mal ejemplo que le dimos», es porque él anduvo en lo mismo, tal como testimonia en la parte VIII de La bohemia de mi tiempo. Palma confiesa con sinceridad socarrona: «Los triunfos escénicos de Márquez y Corpancho despertaron en mí deseo de ensayar mis fuerzas en el drama, y sucesivamente di al teatro tres monstruosidades» (p. 1301). Luego da cuenta de otros dramas escritos por Cisneros, plasmando una serie de juicios críticos, sobre la copia o calco, rasgo defectivo de nuestra literatura que recae no solo sobre el teatro del autor que tratamos, sino sobre el teatro nacional, nuestro teatro:

Hay poca originalidad en el argumento, que parece calcado sobre la escena del alfiler en La Margarita de Borgoña, de Dumas y Gaillardet, y sobre uno de los Cuentos de la reina de Navarra. Alfredo es un Don Juan de pacotilla; pero, en cambio, hay un tipo de beata, que es la Brígida de Zorrilla, mejorada en tercio y quinto. La virreina que nos presenta Cisneros es una virreina de fantasía, y las costumbres que pinta están en lucha abierta con la verdad tradicional o histórica. A pesar de todos sus lunares Alfredo es, entre los dramas que produjo la bohemia, el que mejores condiciones de tal reúne (ibíd.). 
Sin embargo, se entusiasma por los aciertos sobre la lírica y la narrativa de Cisneros:

En cuanto a la versificación, ya se sabe que Cisneros ha sido siempre mimado por Apolo, y que es tan elegante poeta como culto y delicado novelista. Su Julia, más que su Edgardo, es, a mi juicio, una novela de la que pueda enorgullecerse la literatura nacional (ibíd.).

Vallejo, en su tesis, se ocupa de Luis Benjamín Cisneros y José Santos Chocano, dos grandes poetas románticos «que también guardan entre sí una íntima semejanza [...] identificados por Ventura García Calderón»5.

El futuro poeta considera entonces que, Cisneros es un romántico

En toda su obra; y el segundo es en su primera manera, distinguiéndose éste de aquél, porque, en cuanto romántico no soporta ningún refinamiento, ninguna reflexiva orientación en el gusto, mientras que Cisneros, sabe enfrentar su inspiración y la fuerza emotiva en formas delicadamente pulidas y armoniosas, como se puede ver por estos versos:

Mil veces triste, en mi abrasada mano mi frente joven recliné abatida y he preguntado a mi conciencia en vano el último secreto de la vida. (1954, p. 63)

5 Suponemos que Vallejo conocía alguna de las obras de García Calderón, publicadas en los años previos a la sustentación de su tesis: Del romanticismo al modernismo (1910); La literatura peruana 1535-1914 (1914); Parnaso peruano (Antología) 1910-1915. Vallejo, conoció al autor en París y escribió un artículo sobre este «cronista peruano», mencionando Bajo el calor de las sirenas (1919), obra posterior a su tesis. El artículo titulado «Ventura García Calderón», se publicó en el diario El Norte el 28 de marzo de 1924. 


\section{Carlos Augusto Salaverry (Piura, 1830-París 1891) ${ }^{6}$}

La referencia de Palma a Carlos Augusto Salaverry nos hace ver la persistencia en la opción por el drama, y a la vez, el fracaso de los románticos en el logro de dicho género. Palma (1961) afirma que Salaverry es:

El único bohemio que perseveró en escribir para el teatro [...]. Empezó con Abel, El bello ideal, El pueblo y el tirano, Atahualpa, El amor y el oro, y [...] baste decir que pasan de veinte las producciones que él llama dramáticas: pero que, en realidad, no son sino poemitas más o menos ricos de lirismo (p. 1303).

En su concepto, Dios le acordó con profusión de dotes de poeta lírico pero pobrísimo dramaturgo; de allí que sus dramas, como Salaverry los llamaba, eran para Palma solo «poemitas más o menos ricos de lirismo»; así que:

El último de sus dramas es siempre peor que el anterior; y lo que el público aplaude en ellos no es la trabazón metódica ni los caracteres, ni la sombra del diálogo, ni la originalidad de las situaciones, ni la fidelidad histórica, ni lo típico de los personajes, sino lo armonioso, lo lírico, en fin, de sus galanos versos (ibíd.).

Sentenciando: «Atahualpa es acaso, entre todas las obras, la única que puede ostentar algunas de las condiciones del drama» (ibíd.); preguntándose y respondiéndose:

¿Por qué el eminente poeta de Diamantes y perlas y de Albores y destellos, que así se titulan los dos volúmenes de versos que

6 Al momento de su valoración, Palma da cuenta de que Salaverry residía en Europa, atacado de gravísima dolencia, imposibilitado para toda actividad literaria y que murió en París «por los años 1891». 
impresos lleva, y que bastan para inmortalizarlo, persistió en contrariar la voluntad del cielo? iDebilidades y caprichos humanos! (ibíd.).

Vallejo, como hemos visto, hace en su tesis una breve valoración de Salaverry junto con Arnaldo Márquez, porque encuentra

Una gran semejanza entre sus temperamentos artísticos. El primero militar y el segundo diplomático, los dos han cantado en dulcísimas elegías el sentimentalismo romántico más penetrante $[\ldots]$ el tema general y favorito de inspiración es el amor: en Salaverry, el amor a un ángel, como él llama a la mujer objeto de sus sueños, y en Márquez es el amor a su madre (1954, p. 61).

\section{Pero Salaverry es menos místico que Márquez, anota Vallejo:}

La tumba de mis ensueños, tal es en nuestro parecer su mejor composición, por el espiritualismo erótico que la informa, la concepción honda de la vida, y más que todo, por el ansia de inmortalidad que la anima, por las rotundas imágenes delicadamente melancólicas, tiernas, nostálgicas y por la casticidad en la elocución y la sobriedad de los giros. Desengañado del mundo, el joven poeta se despedía de las vanas quimeras de la vida, cantando de este modo:

Quiero un celaje, un lánguido murmullo, un perfume, una queja, algún rumor que sollozando con doliente arrullo repita el eco de mi triste voz! $!^{7}$ (pp. 63-62)

$7 \quad$ Al igual que en el caso de Márquez, Vallejo confiesa las profundas emociones que sentía por la lectura de los versos de Salaverry, su propósito de estudiarlo, de manera «especial y detenida»; a la vez, la imposibilidad de conseguir todas sus poesías. Nos hacemos la misma pregunta: ¿Cómo conoció Vallejo la producción de Salaverry? Sabemos ahora que Salaverry publicó Diamantes y perlas en 1869 , y Albores y destellos en París en 1871, volumen que incluía Cartas a un ángel. 


\section{Conclusiones}

Consideramos importantes las siguientes conclusiones:

1. Las valoraciones que ofrecemos de Palma y Vallejo, complementarias y coincidentes, sobre la obra teatral y la lírica de Márquez, Salaverry y Cisneros, tres bohemios románticos -como apreciamos- son importantes, pero aún incompletas. Hay necesidad de completar la investigación y ver si es que se han integrado a la crítica literaria a dichos bohemios. De no haberse hecho, quedará como un futuro insumo literario significativo.

2. Hemos encontrado también la necesidad de proseguir las investigaciones de la obra La bohemia de mi tiempo de Palma, con el fin de medir su validez integral y crítica, y considerarla base fundamental de los estudios literarios en el Perú, especialmente de la escuela del romanticismo.

3. De igual manera de la obra de Vallejo, sobre todo de aquella que corresponde a su época romántica. Consideramos, por ejemplo, que su tesis sobre el romanticismo en la poesía castellana aún no ha sido suficientemente valorada en sus logros y alcances, pese a las limitaciones que señala con relación a la escasez de los materiales de la obra poética de los bohemios románticos tratados.

\section{Referencias bibliográficas}

Ballón Aguirre, E. (1987). César Vallejo. La Cultura Peruana. (Crónicas). Lima: Mosca Azul Editores.

De la Riva-Agüero, J. (1962). Carácter de la literatura independiente. Obras Completas I. Lima: Pontificia Universidad Católica del Perú. 
Flores Heredia, G. (2018). La tesis de César Vallejo: el romanticismo en la poesía castellana (1915). Propuesta de edición crítica. Tesis para optar el grado académico de doctora con mención en literatura peruana y latinoamericana. Lima: Universidad Nacional Mayor de San Marcos.

Holguín Callo, O. (2010). «La bohemia de mi tiempo: una mirada interna». En revista Aula Palma IX. Lima: Universidad Ricardo Palma.

Palma, R. (1961). La bohemia de mi tiempo. En Tradiciones peruanas completas. Madrid: Aguilar.

Pantigoso, M. (2009). «Hacia el romanticismo de Ricardo Palma y Gonçalvez Días». En revista Aula Palma VIII. Lima: Universidad Ricardo Palma.

Puccinelli, J. (1987). César Vallejo. Desde Europa. Crónicas y Artículos (1923-1938). Lima: Ediciones Fuente de Cultura Peruana.

. (1996). Eleazar Boloña. Escritos Literarios. Lima: Gráfica

Biblos.

Suarez-Murias, M. C. (1963). La novela romántica en Hispanoamérica. New York: Hispanic Institute In The United States.

Vallejo, C. (1954). El romanticismo en la poesía castellana. Tesis. Lima: Juan Mejía Baca \& P. L. Villanueva, editores. Recuperado de https:// fundacionbbva.pe/wp-content/uploads/20 16/04/libro_000030. pdf? $\mathrm{cv}=1$

Recibido el 26 de agosto de 2020 Aceptado el 26 de septiembre de 2020 